bottom of the Polar Sea; for example, at a depth of between 20 and 100 fathoms in the middle of Hinloopen Strait in Spitzbergen, on the east coast of Novaya Zemlya, in the sea east of Cape Chelyuskin, and south of Behring's Straits. At these places the temperature of the sea all the year round is between $0^{\circ}$ and $-2^{\circ} .7 \mathrm{C}$. A temperature at or under the freezing point appears thus to be much more favourable for the development of an abundant animal life at the sea-bottom than one of $15^{\circ}$ to $25^{\circ} \mathrm{C}$., a very remarkable circumstance, which, as far as Nordenskjöld knows, has not received the attention which it deserves. It is to be remarked, however, that the invertebrate animals in the south are larger and finer than in the north, and that the shore fauna, which is entirely absent in the sea of the high north on account of the destructive action of the drift-ice, is here richly developed.

Japan is so poor in land- and fresh-water crustacea, that one often searches for hours in the most favourably situated places without finding a single specimen. Even in the most northerly part of Scandinavia more land crustacea may in many places be collected in a few hours than in Japan in as many days. Lieut. Nordquist, however, has made a fine collection, which is expected to yield many interesting new contributions to the fauna of Japan.

In the numerous dredgings carried on during the royage from Japan to Ceylon at deptbs in which algæ are met with in abundance on the coasts of Scandinavia, not a single alga was brought up by the dredging apparatus. Even in the shore belt marine plants are in many places almost wholly wanting. Some places were found, however, more fortunately situated. The observations made here and the information obtained by an examination of the collections in the museums of Tokio have enabled Dr. Kjellman to obtain a general view of the occurrence of algæ on the east coast of Japan of special interest in many respects in connection with researches carried on by him during the preceding part of the voyage, for example, with respect to the boundaries of the areas occupied by different algæ, with respect to the mutual relation between the abundance of individuals and species at different places, and with respect to the types which are to be considered distinctive of the different areas.

The lichen flora of Japan was examined by Dr. Almquist. In the more elevated regions, as on the sides of the mountain Fusijama, I3,000 feet high below the snow limit, at a height of 6,000 to 8,000 feet above the sea, it has a certain resemblance to that of Scandinavia, but in the low country it is limited to a very few localities. In the purely tropical countries, for instance at Labuan and Singapore, the lichens appear to be confined almost exclusively to the bark of trees, and the whole of this division of the vegetable kingdom here consists mainly of a single group, Sclerolichenes, which occur in abundance and in very varying types.

Prof. Nordenskjöld and Lieut. Hovgaard ascended the mountain Asamajama, a still active volcano, 8,200 feet high, on October 4.

Prof. Nordenskjöld has made extensive collections of fossil plants from fossiliferous strata at Mogi, a fishing village on the coast of Japan, and from the coal-mine Takasima, both in the neighbourhood of Nagasaki, and from the coal-seams at Labuan. The fossils from Mogi lie in a fine white clay slate, and consist almost exclusively of beautiful leaf impressions. At Takasima the fossils consist principally of water plants imbedded in the brownish-black shale which accompanies the coal. At Labuan the fossils lie imbedded in balls of clay-ironstone found in the sandy beds between the coal-seams. They consist of ferns, Cycadece, and large-bladed leaf-trees, which appear to have a tropic stamp, while the Mogi fossils, on the other hand, injicate a moderately warm climate.

\section{AN ELECTRO-DYNAMOMETER FOR MEASURING LARGE CURRENTS}

$T \mathrm{HE}$ use of electric machines of large size for the generation of currents of great strength has become extensive, and promises to increase materially. In connection with this, the best mode of measuring the currents obtained is a matter of much importance as well as one of some difficulty.

Of the possible methods the galvanometric is probably the most used, but it is objectionable as shunts of low resistance must be employed. In general, a method depending upon the estimation of a very small proportional part of the magnitude to be measured is objectionable, since extreme accuracy is necessary and errors of observation are magnified. The mode of measurement by the electro-dynamometer is to be preferred for many reasons, and it has also the advantage of being applicable to to-and-fro currents, as well as to those in one direction. Weber's electrodynamometer is only suitable for measuring very small currents unless shunts are used. Trow-

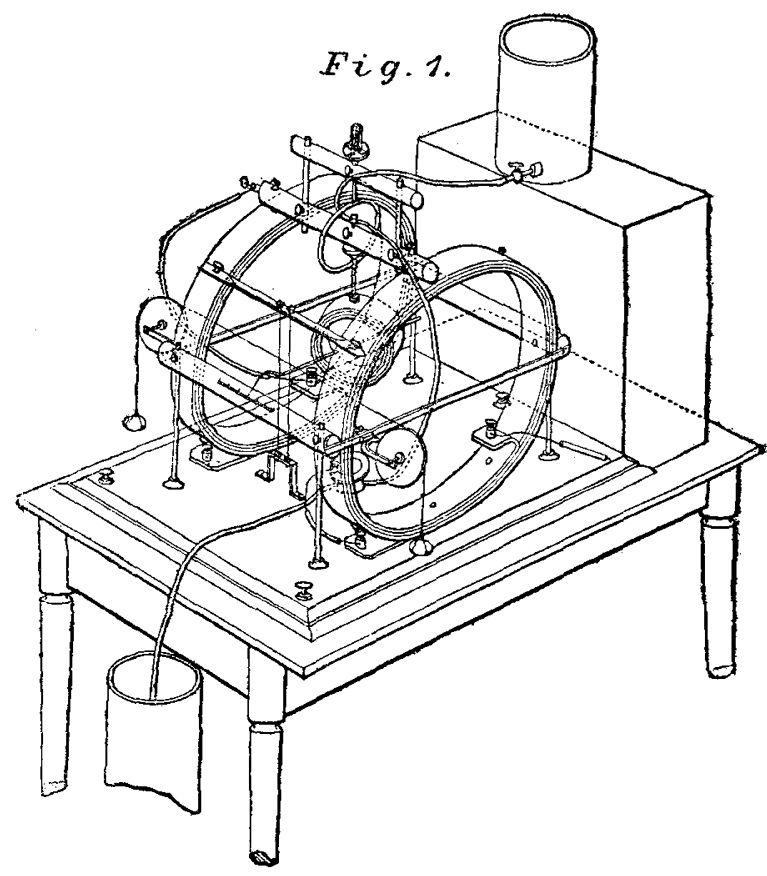

bridge has designed an electro-dynamometer through which large currents may be transmitted and directly measured (Proc. Am, Acad. Arts and Sci., October 9, I878). This instrument works well and gives good results.

During the past year the writer has been experimenting at the U.S. 'Torpedo Station with an electro-dynamometer differing from Trowbridge's in the manner of determining the deflective power of the current, and which seems to present some advantages in simplicity and readiness of working, while especially suitable for technical use. In its general plan, particularly in the arrangement by which the entire current may be passed through the instrument, it follows Trowbridge's form.

Fig. I is a general view of the instrument. Figs. 2 and 3 show the details of the suspended coil. The large, fixed coils are made of thick copper ribbon. The turns are insulated from each other, and the metal framework is insulated from the coils. The suspension arrangement

${ }^{2}$ By Walter N. Hill, Chemist to the U.S. Torpedo Station, Newport R.I., U.S.A. 
is placed on the top of the fixed coils and insulated from them.

The deflecting coil is made of thick copper ribbon fastened with insulated rivets. In its centre, and parallel with it, is a light brass rod or pointer. A copper rod in connection with the outer end of the coil has an iron or nickel-plated point, which dips in mercury contained in a double-walled metal cup, B, on the base-board. A similar rod from the inner extremity of the coil ends in an iron or nickel-plated cup, c, containing mercury. The coil hangs under the metal cylinder, D, so that a plunger, A, in the latter can dip in the mercury in the cup $\mathrm{C}$ of the former. The suspension is of fine sewing silk, waxed or treated with shellac. The thread passes over a little pulley, E, above, with both parts parallel, or nearly so, and close together. As represented in Fig. I, the large coils are connected in series. The current, after traversing the left-hand coil, is led by a wire to the cylinder, D, thence by the plunger, $A$, to the cup, $C$, through the small coil to the cup, $B$, which is connected by a.wire with the righthand coil. In order to prevent heating of the mercury connections, a stream of cold water is passed through the hollow plunger, $A$, and between the walls of $\mathrm{B}$, from a jar above, connected by rubber tubes.

When the current passes, the suspended coil is powerfully deflected, but its actual movement is limited by a vertical wire stop, against which the pointer-rod strikes. To the pointer-rod are attached, on opposite sides, two silk threads which lead over pulleys on the side-bars to small pans, one on each side of the instrument (Fig. I). The pulleys are light, nicely balanced, and turn on hardened steel pivots. When deflection has occurred, weights are added to the pan on the side opposite until the pointerrod returns to its starting-point. A scale is marked on the cylinder in front of the instrument (Fig. I), and a pointer of aluminium wire is fastened to the rod in the centre of the movable coil, so that it traverses the scale (a more convenient mode of noting the return of the coil might be taken). The pans are of the same weight, and the threads by which they are hung are silk fibres. The friction of the pulleys is very small and would be triffing if they were made with jewelled bearings. Also one balances or nearly balances the other, so that practically their friction may be neglected, although allowance might be made for it, if extreme nicety were aimed at. The artxal observation is made when the coil is in the zero position, the weight taken being that required to balance the deflecting force. The movement of the pulleys is then very slight, and the weight acts exactly at right angles to the pointer-rod.

For the measurement of the large currents derived from dynamo-electric macbines, minuteness is not demanded, since the variations due to fluctuations in the currents, alterations in resistance, \&c., are much greater than the limits of observation in such an instrument as this. Quickness and simplicity of working, together with strength and compactness, are required in the electrodynamometer, and this instrument possesses these practical advantages, while it is capable of a good degree of accuracy.

The instrument shown in the figures was made for experimental trial, and is defective in certain details; still it was found to be a good working piece of apparatus.

Theory of the Instrument.--The expression for the strength of current is very simple. The weight found is that required to balance the deflective force and is observed at zero, so that the earth's and local attractions are avoided, nor does the torsion of the suspension enter. Let

$S=$ strength of current in webers.

$w=$ weight used in milligrammes.

$l=$ length of weight-arm, or distance from point where weight acts, to centre of system.

$G=$ constant of large coils. $g=$ constant of small coil.

$C=$ constant of instrument or length of magnetic arm. By the theory of the electro-dynamometer, the force acting to deflect is represented by the expression $\frac{2 \pi n}{r} \times g \times S^{2}$, in which $\frac{2 \pi n}{r}$ is the constant of the large coils or $G$, and $g$ the constant of deflecting coil. This force acts with the arm $C$ and is balanced by the weight acting with the arm $l$. Hence

$$
S^{2}=\frac{l w}{C G g}
$$

The coils being large, $G$ and $g$ are readily ascertained

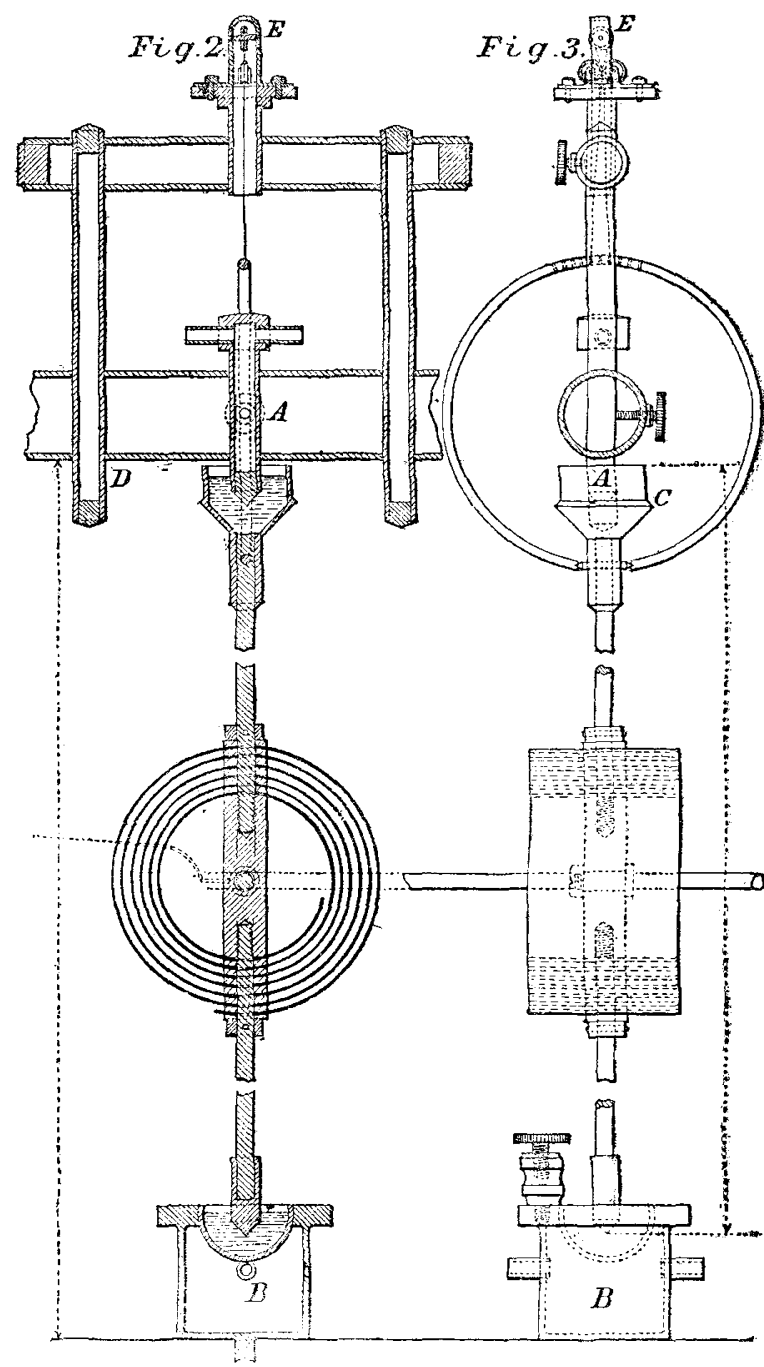

from measurement, and $l$ is a known distance. With the instrument in question, $C$ was found by passing the same currents through it and through Trowbridge's dynamometer, the constant of which was accurately known.

$C, l, G$, and $g$ being known, it is evident that from the observed $w, S$ may be obtained with little calculation. Or, a table may be drawn up from which the value desired can be derived by inspection. Also, a set of weights can be prepared which will represent the current in webers directly. Doubtless this will often be convenient.

The instrument described has been worked with currents as small as Io webers, but it is not quite sensitive enough for such use. With those of 20 webers and upwards it operates satisfactorily. Greater nicety of 
construction would confer greater sensitiveness, and it is probable that this method of observation can be advantageously applied in the construction of instruments for measuring moderate currents. It is, however, evident that this form of the electro-dynamometer is particularly suitable for large currents. We have

$$
S: S^{\prime}:: \sqrt{w}: \sqrt{w^{\prime}} \text {. }
$$

That is, as the current increases, the corresponding weights increase more rapidly and greater accuracy and minuteness are attained.

Thus, as the instrument I have experimented with has been arranged, a current of

20 webers requires a weight of $530 \mathrm{mg}$.

\begin{tabular}{|c|c|c|c|c|c|}
\hline & $"$ & " & $"$ & $580 "$ & $50 \mathrm{mg}$. \\
\hline 49 & " & $"$ & " & 3,165, & \\
\hline (1) & $"$ & $"$ & " & 3,295 & dift. I $30 \mathrm{mg}$. \\
\hline 81 & $"$ & $"$ & $"$ & 8,440 & diff $210 \mathrm{mo}$ \\
\hline
\end{tabular}

while a difference of to $\mathrm{mg}$. is sharply indicated.

My best thanks are due to Prof. John Trowbridge, of Harvard, for advice and the use of his apparatus.

\section{NOTES}

THE Committee appointed by the French Minister of Public Instruction has awarded the Prix de Volta-50,000 francs-to Graham Bell

A translation of "The Skies and Weather Forecasts" of Aratus, by Mr. E. Poste, M.A., of Oriel College, Oxford, will shortly be published by Messrs. Macmillan and Co. These poems, apart from a certain charm in the treatment of the subject, are not without interest as belonging to the literature of infant astronomy and infant meteorology. The meteorology of Aratus is of course merely a specimen of the popular weather wisdom of his day. But the faith it shows in the possibility of a science, and the sense of the importance of such a science, gives him a certain claim to the attention of modern scientific men. The notes to Mr. Poste's translation will be addressed merely to novices in astronomical knowledge.

The New York Times announces the death at Waukegan, Ill., on January 6, of Mr. James W. Milner, at the age of thirty-nine. When barely arrived at man's estate he travelled through Minnesota and the adjoining States, engaged in making collections. At Wankegan Mr. Milner made some remarkable discoveries in the peat-beds, and the remains of an elk which he exhumed were exhibited for quite a number of years in the Chicago Academy of Sciences, until they were destroyed by fire. Such papers as Mr. Milner had written on these remains and on other topics of a a similar character, from their singular terseness and excellence, attracted the attention of the Smithsonian Institution. A correspondence, ensuing between the Smithsonian and $\mathrm{Mr}$. Milner eventually led to his engagement by the present secretary, Prof. Spencer F. Baird, and, in $187 \mathrm{r}, \mathrm{Mr}$. Milner was appointed Deputy United States Fish Commissioner, with the particular duty of studying the habits, food, method of breeding, and catching of the white-fish. From these labours in what some six or seven years ago was quite unknown ground, resulted a work of the most thorough and exhaustive character, which may be cited as a model of patient and elaborate research. From the period of his entrance into the United States Fish Commission his labours were incessant. In the study and development of practical fish-culture, as understood in its widest sense, Prof. Milner may be said to have done more for it than any one else in the United States. His ingenuity and adaptiveness, combined with his thorough grounding in natural history, permitted him to solve many things in fish culture which before his time had been as problems. The wonderful successes he achieved soon made him a leading authority on these subjects, both at home and abroad.
THE death is announced, at the age of sixty-three years, of Mr. David Thomson, Professor of Natural Philosophy in the University of Aberdeen.

M. WALFERDIN, the inventor of the minimum thermometer, died at Paris at the end of January at the age of eighty-five, after a protracted illness of many years' duration. He was one of the members of the Constituent Assembly of 1848 . Since that time he devoted all his leisure to scientific and artistic pursuits. He collected almost every picture drawn by Fragonard, one of the mo.t celebrated French artists of the end of the eighteenth century. He sold his gallery to an English nobleman about twenty years ago, on condition that he should be appointed during his lifetime keeper of the gallery, with a salary of $500 l$. a year, and that the gallery should be exhibited at his own rooms. This precious collection will shortly come to England.

WE regret to state that General Morin, the well-known director of the Conservatoire des Arts et Métiers, is lying in a very precarious state in consequence of a severe cold. Great anxiety is felt for him at the Institute, of which he is one of the most respected and popular members. The General is aged eightyfive years.

ON Monday Prof. W. K. Parker, F.R.S., commences a series of nine lectures at the Royal College of Surgeons, on the Structure and Functions of the Vertebrate Skeleton, to be continued on Mondays, Wednesdays, and Fridays, to the 27 th inst. Prof. Flower, in continuation of previous courses, begins his series of nine lectures on the Comparative Anatomy of Man, on March $\mathbf{r}$, to be continued as above to March 19.

WE are glad to learn that the College of Surgeons have seen their way to the purchase of the Barnard Davis Anthropological Collection, and that Prof. Flower is superintending the removal of the collection to the museum of the College.

THE death is announced of Sir Dominic Corrigan, the wellknown Dublin physician, at the age of eighty years.

ON Tuesday afternoon the problem set by the accidental explosion of the 38-ton gun on board the Thunderer was solved by the explosion of the sister gun with a double loading. The gun was carefully loaded, and then a diagram was painted outside the gun showing the positions of the two charges and their projectiles. First was rammed home the Palliser cartridge of I Io lbs. of pebble powder, next the Palliser shell of I Io lbs., and the papier-mache wad. The second charge followednamely, 85 ibs. of powder, a common shell, and another wad, and the double loading was complete. As marked on the outside of the gun, the $85 \mathrm{lbs}$. of powder lay just in the position where the gun swells in thickness to strengthen the powder chamber. After the firing the little dark cell was found strewn with fragments of the gun, the breech end only of which remained on the carriage, resembling with marvellous fidelity its unfortunate companion now exhibited in the Royal Gun Factories.

WE notice in the January number of the Archives des Sciences Naturelles an interesting letter by Col. Ward, on the meteorology of the high regions of Switzerland during December last. Whilst the valleys were covered with a thick fog, and the sun was visible only for very short intervals, bright sunshine glowed about Rossinières (a small town close by Chateau d'Oex, altitude about 3,240 feet); here the sun was seen daily for twenty-seven days, and twenty-one days were absolutely cloudless. On December 25 Col. Ward climbed Mont Cray, a mountain 6,793 feet high, situated between Rossinieres and Châteaux d'Oex. The view from the top was never so clear and wide; it reached as far as seventy miles in each direction; the mountains of Lake Constance, the Bernese Oberland, Monte Rosa, Mont Blanc, the Vosges, and even the Black Forest, were quite distinguishable, as well as the plateau north of Mont Cray, with the towers of Friburg and Romont. On the contrary, a thick fog covered 